\title{
The Role of Job Stress on Employee Motivation and Performance in the Electric Power Organization of Pakistan
}

\author{
Awais Afzal ${ }^{\text {, }}$, Khyzer Bin Dost ${ }^{\text {b }}$, Syed Adnan Ali ${ }^{c}$, Ehsan Bhutta ${ }^{\text {d }}$ \\ ${ }^{a}$ Department of Business and Management Sciences, The Superior Colleges Lahore, Pakistan \\ Email: awais.afzal968@gmail.com \\ ${ }^{\mathrm{b}}$ Department of Business and Management Sciences, The Superior Colleges Lahore, Pakistan \\ Email: khyzer_bin_dost@hotmail.com \\ ${ }^{c}$ Department of Business and Management Sciences, The Superior Colleges Lahore, Pakistan \\ Email: adnanaligooo1@gmail.com \\ d Department of Business and Management Sciences, The Superior Colleges Lahore, Pakistan \\ Email: ehsanbhutta69@gmail.com
}

\begin{tabular}{l}
\hline ARTICLE DETAILS \\
History: \\
Accepted 22 Nov 2020 \\
Available Online 31 Dec 2020 \\
\hline Keywords: \\
Effect of Stress, Job Motivation, \\
Job Stress, Organization, \\
Employee \\
\hline JEL Classification: \\
C39, J28, J29 \\
\hline
\end{tabular}

DOI: $10.47067 /$ reads.v6i4.276

\section{ABSTRACT}

The aim of this study to decrease the stress factors and improves the motivational level and performance of the organization. Job stress create the role conflict, lake of feedback, unregularly, disordering, psychological and physical effect. In this study we minimize the stress level and improve the motivational level and performance. The questioners were distributed among employee contribution the information of the seniors, graduate employee, including customer's service and manager of well reputed rising organization in Pakistan. The 300 questioners distributed response of questioner was 255 the information was got through close ended questionnaire. The statically test of regression, correlation, reliability were also measured. The significances are remarkable with negative correlation between job stress and motivation and disclose that job stress prominently shortens the motivation of a specific. The consequences propose to the organization that they have maintained a very healthy cooperative and amiable atmosphere with in the group for best motivation. The value of this study is to disclose stress full and motivational elements for the workers in the organization. So to complete this purpose further sub objective are maintained to find out element that can cause job stress and elements that can motivate the workers institution and highlight influence of job stress and availability of motivational elements on the performance of the workers in the organization.

(C) 2020 The authors. Published by SPCRD Global Publishing. This is an open access article under the Creative Commons Attribution-

NonCommercial 4.0

Corresponding author's email address: khyzer_bin_dost@hotmail.com

\section{Introduction}

The world is making progress by leaps and bounds at a constant ratio. To tackle with this heart 


\section{Review of Economics and Development Studies, Vol. 6 (4) 2020, 759 - 772}

core contest organization adopts divergent skills and planning. In spite of these policy and tricks on element that I am being able to perform its essential part to develop organization in gaining valuable profit is its employees.

The workmen are the compulsory, hot and soul of every business organization and institution. To handle all the operational activity of successfully adventurous, it is reasonable that work man must do great struggle in scouring institutional motives. There are institutions that try their hard to achieve success and invent impressive policy to keep the mood of their employees comfort and stress less. The directors are try to do hard work to motivate work men to do their best effort. By developing stress less elements from the work life and by meaning the provision of motivational elements manager supervisor and the director can enable the workmen consoled by the improve the capability of the laborers the main motive of this research is to find painful and motivational elements for the workmen.

Now a day in universe stress is determined as a world recommended hard core issue which presents in everywhere in different forms of work. Today we are talking about work life the workmen are normally working for a longer time as improving the scale of responsibility which are responsible to make them more hard working to meet proposed desires about their work performance. Omolara (2008) defined professional emphasis to the opposite mental and bodily responses which happens in a personal the outcome of their unable to handle the requirement ready for them. In the opinion of swanepoel (1998) performance associated emphasis which is subject matter which have taken a growing focus in the field of professional better physical condition for previous thirty years. These writers had the ideas the universe particularly the universe of information and trade has made improvingly inclined to swift moving factors such as much more contest, the stress of standard creation and improvement in the realm of running trade. The requirement on the workers develops as same swiftly and in this way emphasis develops among the workers. Besides, emphasis which develops from the performance condition the means of emphasis might associate to individual elements like linkage with the any one and apply of the spare time.

Emphasis may be narrated the opposite mental and bodily responses which happens in the personal the outcomes of male and female unskilled to handle the requirement which are prepared for male and female (Moorhead and Griffen, 1998). It is complicated which is develop from useless requirement from the personal.

It is copy down that emphasis is not essentially wrong; this is a chance when his provide energetic achievement. But everything its behavior commonly starts when persons are put in a performance atmosphere which is unsuitable the way in which they perform their work technique and tempo. This makes embarrassed when the personal search for that they have and may do a slight grip on it.

There are number of institution in the cosmoses are viewing a dangerous enhancement of the wrong impacts of emphasis on the workers encouragement. Traditional instances are institutional in America, in the United States, the Caribbean, the east and central Africa, West Africa and in the different portion of the universe. An American academy of family doctor's viewed the information about two third of the consultant pay a visit to a family doctors are the consequence of emphasis associated symbols.

A lots of organization with the purpose of achieving greater creativity since frustrated workers a with extra output to handled dangerous line and this must be mental and bodily impacts on the worker 
Review of Economics and Development Studies, Vol. 6 (4) 2020, 759 - 772

which cause outcomes which is totally oppose to the what these institution wish to gain. Yet institution focusing deep attention then in the previous time the result of the trauma their workers spend when they put useless requirements on them. There is still more time for achievement. Again to develop enough money to be self-maintain and to be able to collect the fund in the taking of latest tools meant able service provision and optimal opportunity of the means.

In the opinion of Lazarus (2003) stress is a scenario that is multi-dimensional. This scenario can be accepted a serious thing for any institution as it make the reasons of overwork employee septum over (Villanueva and jukovic, 2009) the element of stress consider greatly a vital issue for organization and industry that are employee created. This is because work man has to handle quarreling requirement of company, clients and supervisor. These confusion between the employees and the supervisor may speak out the dissonance for employee.

Previous investigations clear it is very common settlement the institution asking the problems of emphasis and institution are getting busy to try to decrease the emphasis it is a worldly and famous motive, but it can be possible in decreasing the consumption of the worker (Cooper and Dew, 2008). Investigation procedure associated to emphasis for institution it is kind of subject which is under discussed but it has sufficient energy to influence the life of the people in a right full method by improving useful for the main core elements of emphasis assisting tools may be offered to the employees in the institution to highlights their outputs. It is due to this cause, it is comparable to held investigation in the institution to find out the kinds of elements that develop stress for the workers. Stress is natural part of life that invents whenever they are greater change in our life if right and wrong. It is seriously impacted that human being handled various type of stressor in case of their understanding. Stressors are associated to the work environment and the people. Stress is the reaction of the psychical body owing to inter contacting with any instigative in the atmosphere. Job stress reasons various psychological issue such as anger, depression, irritability and tension; this impact the motivation of worker wrongly. Stress and motivation have opposite linkage; when the stress promote the motivation is going to come down.

\section{Significance of the Study}

The main motive of the theory is to search for influence of stress on the workers encouragement. The investigator trust that this theory is very vital and would run for long time to copy all the institution very unique those in the service field at the requirement to enable the positive administration of stress for their workers. The theory will also increase to maintain the vocabulary of information. So people in the various part of the homeland try to handle the issue this will also offer views how to decrease the impact of stress at production. Once again this will be a mean for more investigation and totally associated to shareholders.

The basic purpose of this philosophy is to disclose stress full and motivational elements for the workers in the institution. So to complete this purpose further sub objective are maintained these are as under:

1. To investigate element that can cause job stress.

2. To investigate influence of job stress and availability of motivational elements on the performance of the workers in the organization.

3. To investigate the elements that causes the job stress and recommendation to the director of organization to apply motivational elements and to point out elements that minimize the stress and improve the performance. 


\section{Literature Review}

The heading literature review means revised and highlighting of presents theories and provides sources data associated to the heading of an investigation. Spector (2007) revises that literature review is the motive of highlighting of the current structure of knowledge and information. When an investigator starts the journey to disclose hidden facts and modern approaches in the field of knowledge it is an essential at task review in the literature at the same time handling the procedure is also comparable to the theory.

Due to the swift changing world in the financial scenario people have to serve under huge pressure at their designation. A large and various areas in literature point out maximum winning element like work, situation, administration, help, work pressure, and recognize the stressful work can be influenced and its impact on the psychological and physical health of the workers. Work position be presented in every institution big and small at work areas and institution have develop, therefor greatly complicated owing to occur at the work area and institution have develop so must difficult due to which it exists work place has stressed important impact above the worker job ability and the institution by way of well.

Job related stress in specific is the failure to holder with the stress in a job for the reason that of a poor suitable between somebody's skills and his work necessities and situations (Rytkon and Strandvik, 2005). It is a psychological and physical situation which has emotional impact an individual's production, efficiency, individual strength and value of work. It is also experimental that work-related stress has been related with fatigue, which is well thought-out, a produce of long period contact to stress (Burke and Green glass, 1994; Mearns and Cain, 2003).

It is formally linked with for the time being and chronic diseases, like headache, hypertension, reduce immune response, stomach complaints, depression, and stock (Ashcraft, 1992; Burke and Green glass, 1994; Kahn and Byosiere, 1992; Kyriacou and Sutcliffe, 1977).

\subsection{Stress}

The theme of the topic stress makes a dimensional important as the application of the words enhances. The latest introduction which are propounded by the men of letters researcher and investigator relevance that it may be explained as the individual knowledge of an individual which is reasons by the develop pressure extra and useless and suitable requirement. Emphasis impact the competency of a personal to handled or this would be accurate to give in the right way which impacts the conception of a personal about the individual capabilities that male and female owns (Ricardo, Amy and Rohit, 2007).

\subsubsection{Job Stress}

Stress associated to task happen when the requirements of job the means and efficiency of personal employees are totally various. In few matters may be right full and impact market place in the very fruitful way by enabling the workers to find out traits of the worker and by highlighting the carefulness of the worker (Ricardo et al., 2007). It is unique scale of emphasis which can enhance energetic benefits in the capability of the institution. The emphasis makes extra and over the scale increase that it become unsecure. In these matters it is not only impact the motivation of the workers but this enhances the rate of institution like medical treatments and develops outputs (Hassan, et al., 2020). 


\subsubsection{Job Stress and Employees}

Presenting to Dyck (2001) the standard of life of worker may be badly impacted to job emphasis. In the advanced a progressing country the very vital issue which is health danger in which workers are highlighted is job emphasis. Spector (2007) moreover highlight that there are lots of elements which are the cause of job emphasizer. The job emphasizer may handle the given work and the emphasized for the workers no issue if they are the employees of the productive business. To this in the enhancement of the issue their emphasizers like interpersonal association at market place like there is objection against the term and conditions of the administration opposite view against the conduct of the superior authority, and disagree with the assistant with the coworkers (Deng et al., 2019).

\subsubsection{Factors that Cause Stress}

Conception of people in the UK employees associated to emphasis illness is may be correct at the foundation of only clarity of emphasis associated sickness. In the last century nineteen ninety at the beginning of the twenty century the scale of emphases was checked out to be its highest level in the UK employees. In the back of his scale of emphasis the next causes were right down (Ricardo et al., 2007).

- The very vital elements in the back of the highest scale of emphasis was countless work load pressure.

- Instead of extra work load there are lots of elements like sexual are cultural blackmailing reducing the members of staff, working in the shifts, at once changing threatening working extra and long hours are the root cause of emphasis which totally associated to the work load pressure.

In the meantime 2000, a slight happening in the related value of any of the associated to emphasis of task is maintained (Ricardo et al., 2007). Task, emphasis may happen due to various elements like as personal, socio-economic and family affairs (Swanson, 1998).

\subsubsection{Job Stress and Employees in organization}

In the institution like that it demands the worker to encounter unhappy practices enable the worker try their hard an enquiry the workers to perform the job in difficult hours. Working hours in an institution may be various from institution to institution. Working hours also insist progresses of the job (Kokoroko and Sanda, 2019).

In the institution, major changing is happened. The scale of contras has also developed for this enhances the load of task and requirements. So emphasis of workers is one of most centered issue in the institution the staff output proportion is the upgraded in the institution and the main cause behind this is the emphasis and task pressure (Pulak, 2012).

\subsection{Motivation}

The view of motivation is not modern in the sphere of human means administration. There are numbers of men of letter have explained and suggested it is the term in many spheres and they have offer various translation to motivation of the workers. So many explanations have clear views. At the main point of mental study human knowledge and money motivation consulted to one cause or many which make a person to get indulged in a certain conduct (Bratton and Gold, 2007). From this point a man may be many point and basic demands like meal and wish for a condition being or a thing can be involved in this cause for motivating a person to behave in a particular methods or to do unique performances. 


\subsubsection{Motivation and Employees}

This is clarify that Chon (2012) the dedication of work man outcomes and retaining of creative work potential it is very vital for administration to develop working situation and motivate the worker reasonably. They are demanded to understand the encouraging procedure requirement of human means in different societies (Han et a., 2019).

\subsubsection{Employee Motivation in Organization}

On behalf of the previous many years, motivation among workers in institution is a fascinating subject for a many of investigators and researchers. The workers incentive in administrations can be examined with their attentiveness, pleasantness, exterior and their conduct. Besides, the methods they perform their job duties and do their subjective tasks fix their motivation scale in their job (St-Onge et al., 2009). In other way, the workers 'presentation in institution and inns should make greater consolation so as to make continual business with them. Therefore, the achievement of an institution certainly extremely needy on how well the front-runners and administration manage their work in this kind of institution. This clears that more important benefit of the administrations in the labor force counting institution and non-management workers (St-Onge et al., 2009).

\section{Theoretical Model and Hypothesis}

This study present the main model by which to determine the role of job stress (variable workload pressure, performance pressure) on employee motivation(intrinsic, extrinsic) and performance. The work load pressure and performance pressure are used to measure the motivation and performance. Furthermore the independent variable work load pressure and performance pressure the mediation variable intrinsic motivation extrinsic motivation and the dependent variable performance.

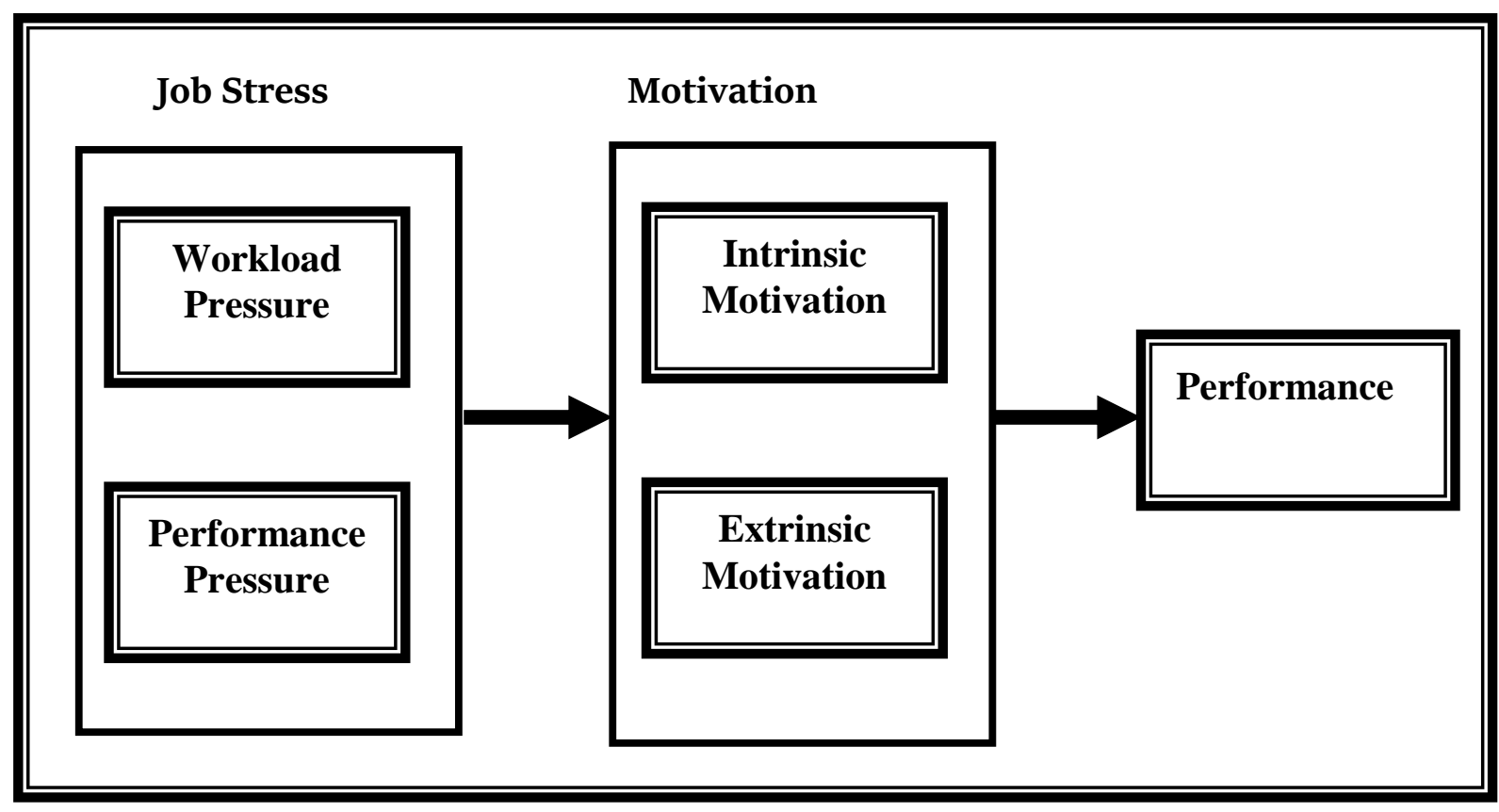

H1: There is positive relationship between work load pressure and intrinsic motivation. $\mathrm{H} 2$ : There is positive relationship between work load pressure and extrinsic motivation. H3: There is positive relationship between performance pressure and intrinsic motivation. $\mathrm{H}_{4}$ : There is positive relationship between performance pressure and extrinsic motivation. $\mathrm{H}_{5}$ : Intrinsic motivation mediates the relationship between workload pressure and performance H6: Extrinsic motivation mediates the relationship between workload pressure and performance. 
Review of Economics and Development Studies, Vol. 6 (4) 2020, 759 - 772

H7: Intrinsic motivation mediates the relationship between performance pressure and performance. H8: Extrinsic motivation mediates the relationship between performance pressure and performance.

\section{Research Methodology}

\subsection{Research Paradigm and approach}

The research approach is based on a real problem that requires a solution. For this study positvision has been selected as it based on objective reality, existing theories, acceptable and unbiased knowledge, quantifiable variable and statistical analysis (Creswell, 2013). Furthermore, deductive inquiry approach is used and it is an associational study that aims to examine the relationship among proposed hypotheses (Fraenkel, Wallen, and Hyun, 1993). The positivist's paradigms and the deductive approach are appropriate to test the theoretical research model and to examine effects (franenkel et al., 1993).

\subsection{Sample}

The population included power organization interested in improving the quality of employee. Data regarding job stress variable workload pressure, performance pressure motivation and performance from power organization. Questionnaire was distributed 300 hundred responded 255.

\subsection{Statistical Analysis Techniques}

There are various statistical techniques that were used to find out the results. For the example, reliability and validity test were performed to measure the internal consistency and construct validity of scale. Where liner regression, mediation, and Aguinis (2004) multiple moderation regression test were used to examine the relationships in proposed hypothesis.

\subsection{Instrumentations}

Sekaran (2006) explained self- administered questioner as the best data collation tools as selfadministered questioners can be helpful in collection data at low cost, required less effort, pose minimum travelling cost, and do not require the physical presence of the researcher (Babbie,2015).

A twenty five item questioner was adapted to evaluate job stress employee motivation and performance. This study used a five-point Likert scale that ranged from $1=$ strong disagree to $5=$ strong agree. Exploratory factor analysis is used to examine the construct validity of adapted scales as well as to evaluate the structure of association between variables used and respondents. In this instance, factor analysis was conducted using PCA with a varimax approach. In Table 1, Bartlett's test of spharicity has found significant e for collected data for factor analysis. Furthermore, a sampling adequacy test shows a significant sample and good relationship among variables. KMO sampling adequacy has indicated the appropriateness of these factors. Moreover, Bartlett's test and P-values are also significant; therefore, factor analysis was performed.

Table 1: KMO and Bartlett's Tests

\begin{tabular}{|c|c|c|c|c|}
\hline Variable Description & $\begin{array}{c}\text { Scale } \\
\text { Items }\end{array}$ & $\begin{array}{c}\text { KMO Measure of } \\
\text { Sample Adequacy }\end{array}$ & $\begin{array}{c}\text { Bartlett's Test of } \\
\text { Sphericity\& Chi- } \\
\text { Square }\end{array}$ & $\begin{array}{c}\text { Bartlett's Test of } \\
\text { Sphericity sig. }\end{array}$ \\
\hline Intrinsic Motivation & 5 & .862 & 1753.12 & .000 \\
\hline Extrinsic Motivation & 5 & .753 & 1230.75 & .000 \\
\hline Performance Pressure & 5 & .782 & 1012.90 & .000 \\
\hline
\end{tabular}

Exploratory factor analysis and confirmatory factor analysis were, used on initial responses for 
Review of Economics and Development Studies, Vol. 6 (4) 2020, 759 - 772

measuring the construct's validity for those scales which were adapted to fulfill the aims for this study. By using exploratory factor analysis, the five-item of intrinsic motivation and methods has retained that loaded on its original factor. Furthermore, five items of performance were retained on its original factor. Finally, all three items of extrinsic motivation scale have loaded on its original factor. In Table 2, only those values are presented that have Eigen-value> 1. Furthermore, three components were selected based on higher Eigen-values. These components are called principle components. Intrinsic motivation has five-items and is demonstrated $66.49 \%$ variance, and extrinsic motivation was measured based on five-item which indicated $77.79 \%$ variation. Finally, the performance scale consisted of five items and indicated $68.20 \%$ variation.

Table 2: Eigen-values and total variance explained

\begin{tabular}{|c|c|c|c|c|}
\hline \multirow{2}{*}{ Constructs } & Components & Total Var. & $\begin{array}{c}\text { Eigen-values } \\
\text { \% of Variance } \\
\text { Explained }\end{array}$ & $\begin{array}{c}\text { Cumulative } \% \\
\text { of Variance } \\
\text { Explained }\end{array}$ \\
\cline { 3 - 5 } & & & 66.49 & 66.49 \\
\hline Intrinsic Motivation & $1^{\text {st }}$ Comp. & 3.32 & 77.79 & 77.79 \\
\hline Extrinsic Motivation & $2^{\text {nd }}$ Comp. & 2.55 & 68.20 & 68.20 \\
\hline Performance Pressure & $3^{\text {rd }}$ Comp. & 2.35 & \multicolumn{3}{|c|}{} \\
\hline
\end{tabular}

Confirmatory factor analysis (CFA) was conducted to measure the model fit for proposed hypothesis testing. For measuring the model validity, there are different standards, namely the "Tucker-Lewis Index (TFI), Comparative Fit Index (CFI), Root-mean Square Error of approximation (RMSEA), Goodness of Fit Index (GFI), and Adjusted Goodness of Fit Index (AGFI)". Following the same, RMSEA standard benchmark was 0.08 or below, CFI, GFI, AFGI, TLI standard was o.90 or above, whereas CMIN/df standard for acceptance was <3. Initially, there was weak model fit statistics. However, modification indicates were extracted to get good model fit statistics (See Table 3 )

Table 3: CFA Results

\begin{tabular}{|c|c|c|c|c|c|c|}
\hline Descriptions & CMIN/DF & CFI & TLI & RMSEA & GFI & AGFI \\
\hline Weak Model Fit & 4.271 & .731 & .71 & 0.78 & .723 & .809 \\
\hline Good Model Fit & 3.01 & 0.890 & 0.874 & .085 & .911 & .901 \\
\hline Threshold-Model fit & $<3$ & $\geq 0.91$ & $\geq 0.90$ & $\leq 0.81$ & $\geq 0.93$ & $\geq 0.92$ \\
\hline
\end{tabular}

\section{Results and Analysis}

\subsection{Reliability Measurement}

Table 4: Reliability Measurement

\begin{tabular}{|c|c|c|}
\hline Variables Descriptions & Total Items & Cronbach Alpha \\
\hline Intrinsic Motivation & 5 & .877 \\
\hline Extrinsic Motivation & 5 & .825 \\
\hline Performance Pressure & 5 & .850 \\
\hline
\end{tabular}

Reliability analysis has conducted to examine the Cornbach's alpha values to measure internal consistency of each construct. The results have revealed that all Cornbach's alpha values vary from $.877, .825$ and .850 respectively of the above variables table 04 that are significant and align with the 
acceptable standards.

\subsection{Descriptive Analysis}

Table 5: Descriptive Statistics Results

\begin{tabular}{|c|c|c|c|c|c|}
\hline Variables Description & Valit-N & Mean & Std. D & Min. V. & Max. V. \\
\hline Workload Pressure & 255 & 3.31 & 0.549 & 1 & 5 \\
\hline Performance Pressure & 255 & 3.09 & 0.844 & 1 & 5 \\
\hline Intrinsic Motivation & 255 & 3.11 & 0.737 & 1 & 5 \\
\hline Extrinsic Motivation & 255 & 3.97 & 0.367 & 1 & 5 \\
\hline Performance Pressure & 255 & 2.97 & 0.436 & 1 & 5 \\
\hline
\end{tabular}

Descriptive analysis has performed to find the valid-N for each item, average values, standard deviation, minimum range and maximum range values. In Table 5, all the extracted means values vary from neutral to strongly agree.

\subsection{Linear Regression Analysis}

Table 6: Linear Regression (Workload Pressure and Performance Pressure)

\begin{tabular}{|c|c|c|c|c|c|}
\hline \multirow{2}{*}{ Variables Description } & \multicolumn{5}{|c|}{ Performance } \\
\cline { 2 - 6 } & $\mathrm{R}^{2}$ & F-value & Un. Std. $ß$ & T-value & P-value \\
\hline Workload Pressure & .312 & 83.55 & .384 & 3.45 & 0.000 \\
\hline Performance Pressure & .422 & 127.54 & .509 & 5.64 & 0.000 \\
\hline
\end{tabular}

A linear regression test was applied to determine whether or not there was a relationship between job stress and performance. In Table 6 , the $\mathrm{R}^{2}$-value (0.312) means performance changed significantly with workload performance. Furthermore, un-standardized $\beta$ coefficients and P-values indicated a statistically significant relationship between workload pressure and performance $(ß=0.312$, $\mathrm{p}<0.005)$. In the same way, the $\mathrm{R}^{2}$-value $(0.422)$ showed that performance was influenced significantly by performance pressure. Moreover, un-standardized coefficients and P-values demonstrated strong and statistically valid relationship between performance pressure and performance $(\Omega=0.422$, $\mathrm{p}<0.005)$.

\subsection{Mediation Analysis}

Preacher and Hayes (2004) test has been used to examine the mediation effects of job stress variable and extrinsic motivation among workload pressure and performance.

Table 7: Mediation Test ((Workload Pressure, Intrinsic Motivation and Performance)

\begin{tabular}{|c|c|c|c|c|}
\hline Statistical description & $\begin{array}{c}\text { A-Path } \\
\text { X-M }\end{array}$ & B-Path ${ }^{1} \mathrm{M}(\mathrm{X}) \mathrm{Y}$ & $\begin{array}{c}\text { C-Path } \\
\text { X-Y }\end{array}$ & $\begin{array}{c}\text { C-Path }^{1} \\
\text { X(M)Y }\end{array}$ \\
\hline Un-standardized $ß$ & .581 & .401 & .507 & .311 \\
\hline P-value & .000 & .000 & .000 & .000 \\
\hline T-value & 10.14 & 6.19 & 5.11 & 4.01 \\
\hline $\mathrm{R}^{2}$ & \multicolumn{3}{|c|}{.501} \\
\hline Adjust R & .492 \\
\hline Significance value & \multicolumn{3}{|c|}{85.14} \\
\hline F-value & \multicolumn{3}{|c|}{} \\
\hline
\end{tabular}


A-Path ${ }^{1}$ revealed a significant and positive relationship between workload and performance $(\Omega$ $=0.581, \mathrm{~T}=10.14$ at $99 \%$ confidence level). All four steps of the mediation effects were significant (See Table 7). C and C'-Path ${ }^{1}$ indicated the direct and indirect association shows that, intrinsic motivation partially mediated the relationship between workload and performance. The overall results of mediation were statistically significant $\left(\mathrm{R}^{2}=0.501\right.$ and $\mathrm{F}$-value $\left.=85.14\right)$.

Table 8: Mediation Test ((Workload Pressure, Extrinsic Motivation and Performance)

\begin{tabular}{|c|c|c|c|c|}
\hline Statistical description & $\begin{array}{c}\text { A-Path } \\
\text { X-M }\end{array}$ & B-Path $^{1} \mathrm{M}(\mathrm{X}) \mathrm{Y}$ & $\begin{array}{c}\text { C-Path }^{1} \\
\text { X-Y }\end{array}$ & $\begin{array}{c}\text { C-Path }^{1} \\
\text { X(M)Y }\end{array}$ \\
\hline Un-standardized $\beta$ & .533 & .378 & .486 & .313 \\
\hline P-value & .001 & .003 & .010 & .009 \\
\hline T-value & 10.19 & 5.88 & 9.51 & 4.95 \\
\hline $\mathrm{R}^{2}$ & \multicolumn{3}{|c|}{.453} \\
\hline Adjust R ${ }^{2}$ & \multicolumn{3}{|c|}{.002} \\
\hline Significance value & 65.19 \\
\hline F-value & \multicolumn{3}{|c}{} \\
\hline
\end{tabular}

A-Path1 reported a significant and positive relationship between workload and performance $(\Omega=$ o.533, $\mathrm{T}=10.19$ at $99 \%$ confidence level). All four steps of the mediation effects were significant (See Table 8). C and C'-Path ${ }^{1}$ indicated the direct and indirect relationship between workload and performance. The overall outcomes were statistically significant $\left(\mathrm{R}^{2}=0.453\right.$ and $\mathrm{F}$-value $\left.=65.19\right)$.

Table 9: Mediation Test ((Performance Pressure, Intrinsic Motivation and Performance)

\begin{tabular}{|c|c|c|c|c|}
\hline Statistical description & $\begin{array}{c}\text { A-Path } \\
\text { X-M }\end{array}$ & B-Path $^{1} \mathrm{M}(\mathrm{X}) \mathrm{Y}$ & $\begin{array}{c}\text { C-Path }^{1} \\
\text { X-Y }\end{array}$ & $\begin{array}{c}\text { C-Path }^{1} \\
\text { X(M)Y }\end{array}$ \\
\hline Un-standardized $\beta$ & .388 & .403 & .387 & .298 \\
\hline P-value & .000 & .000 & .000 & .001 \\
\hline T-value & 5.94 & 6.03 & 5.81 & 4.51 \\
\hline $\mathrm{R}^{2}$ & \multicolumn{3}{|c|}{.401} \\
\hline Adjust $\mathrm{R}^{2}$ & \multicolumn{3}{|c|}{593} \\
\hline Significance value & \multicolumn{3}{|c|}{55.49} \\
\hline F-value & \multicolumn{5}{|c|}{} \\
\hline
\end{tabular}

A-Path ${ }^{1}$ showed a significant and positive relationship between performance pressure and performance $\left(\Omega=0.388, T=5.94\right.$ at $99 \%$ confidence level). $C$ and $C$ '-Path ${ }^{1}$ showed direct and indirect association's that, intrinsic partially mediated the relationship between performance pressure and performance (See Table 9). The overall statistics were statistically significant $\left(\mathrm{R}^{2}=0.401\right.$ and F-value $=$ 55.49) 
Review of Economics and Development Studies, Vol. 6 (4) 2020, 759 - 772

Table 10: Mediation Test ((Performance Pressure, Extrinsic Motivation andPerformance)

\begin{tabular}{|c|c|c|c|c|}
\hline Statistical description & $\begin{array}{c}\text { A-Path } \\
\text { X-M }\end{array}$ & B-Path $^{1} \mathrm{M}(\mathrm{X}) \mathrm{Y}$ & $\begin{array}{c}\text { C-Path }^{1} \\
\text { X-Y }\end{array}$ & $\begin{array}{c}\text { C-Path } \\
\text { X(M)Y }\end{array}$ \\
\hline Un-standardized $\beta$ & .388 & .403 & .387 & .298 \\
\hline P-value & .000 & .000 & .000 & .001 \\
\hline T-value & 5.94 & 6.03 & 5.81 & 4.51 \\
\hline $\mathrm{R}^{2}$ & \multicolumn{3}{|c|}{.401} \\
\hline Adjust $\mathrm{R}^{2}$ & \multicolumn{3}{|c|}{.393} \\
\hline Significance value & \multicolumn{3}{|c|}{55.49} \\
\hline F-value & \multicolumn{3}{|c}{} \\
\hline
\end{tabular}

A-Path ${ }^{1}$ revealed positive link between performance pressure and performance $(ß=0.388, \mathrm{~T}=$ 5.94 at $99 \%$ confidence level). It is evident that extrinsic motivation partially mediates the relationship between performance pressure and performance. The overall values were statistically significant $\left(\mathrm{R}^{2}=\right.$ 0.401 and $\mathrm{F}$-value $=55.49$ ) table 10.

\section{Conclusion}

It is the purpose of this philosophy was to maintain how the workers job encouragement in an organization may be develop by the decreasing of job associated stress and by encouraging the worker. For the development and the promotion of the institution this is essential that workers are contented with their work only this is the way they may be capable to do their task in a very impressive way while an institution administration of difficult work and it may develop this contentment with in the worker if it does not mange or handle positively and wholly. The human means specifically in the institution trade perform a very significant part in the improvement of the business in any kind of institution commerce peoples are answerable for rendering the output to the other there for the complete output of the commerce is relied on the output of the worker. In this sense believing the worker output is extra ordinary can be viewed the very vital element to pounder over. At the current market condition where there is a chain of contras so to sustain in the contestant market is essentially for institutional trade to offer the highest capability and skills.

It is the motive of this philosophy was to maintain how the workers job encouragement in an institution may be develop by the decreasing of job associated stress and by encouraging the worker. For the development and the promotion of the institution this is essential that workers are contented with their work only this is the way they may be capable to do their task in a very impressive way while an institution administration of difficult work and it may develop this contentment with in the worker if it does not mange or handle positively and wholly. The human means specifically in the institution trade perform a very significant part in the improvement of the business in any kind of institution commerce peoples are answerable for rendering the output to the other there for the complete output of the commerce is relied on the output of the worker. In this sense believing the worker output is extra ordinary can be viewed the very vital element to pounder over. At the current market condition where there is a chain of contras so to sustain in the contestant market is essentially for institutional trade to offer the highest capability and skills.

\section{Theoretical and Practical Implications}

The consequences are remarkable with negative correlation between job stress and motivation and disclose that job stress prominently shortens the motivation of a specific. The consequences propose to the institution that they have maintained a very healthy cooperative and amiable atmosphere with in the group for best motivation. 


\section{Limitations ad Future Directions}

Shortage of time which has been defined to deal this study is very limited for the collection of lots of data and this is the limitation which have to be parted with the central academic task which concluded and getting ready in confronted discussion and trials. It is a main issue in offering the requirements efforts for the investigated information. Few answerable people did not help the investigator in the time information data and knowledge collection and assembling. This study has conducted only electric power organization.

\section{REFERENCES}

Aguinis, H. (2004). Regressin analysis for categorical moderators: Guilford Press.

Anderson, S. E., Coffey, B. S., \& Byerly, R. T. (2002). Formal organizational initiatives and informal workplace practices: Links to work-family conflict and job-related outcomes. Journal of management, 28(6), 787-810.

Ashcraft, D.M (1992). Health in the Workplace. In Kelley, K. (Ed.), Issues, Theory, and Research in industrial / Organizational Psychology (pp.259-283). Amsterdam: Elsevier Science Publication B.V.

Babbie, E. (2015) The practice of social research: Cengage Learning.

Bernhardt, A., Dresser, L., \& Hatton, E. (2003). The coffee pot wars: Unions and firm restructuring in the hotel industry. Low-wage America: How employers are reshaping opportunity in the workplace, (pp. 33-76).

Blakely, T. A., Collings, S. C., \& Atkinson, J. (2003). Unemployment and suicide. Evidence for a causal association? Journal of Epidemiology and Community Health, 57(8), 594-6oo.

Bratton, J., and Gold, J. (2007), "Human Resource Management: Theory and practice”

Burke,R.J., \& Green glass, E. (1994). A Longitudinal Study of Psychological Burnout in Teachers. Human relation, 47(3), 1-15.

Chon, K. S., \& Yu, L. (2012). The international hospitality business: Management and operations. Routledge.

Comish, R., \& Swindle, b. (1994), Managing stress in the workplace. National Public Accountant, 39(9), 24-28.

Cooper, C., \& Dewe, P. (2008). Well-being-absenteeism, presenteeism, costs and Challenges. Occupational medicine, 58(8), 522-524.

Creswell, J. W. (2013). Research design: qualitative, quantitative, and mixed methods approaches: Sage Publications.

Deng, J., Guo, Y., Ma, T., Yang, T., \& Tian, X. (2019). How job stress influences job performance among Chinese healthcare workers: a cross-sectional study. Environmental health and preventive medicine, 24(1), 2.

Dyck, D. (2001). The toxic workplace. Benefits Canada, 25(3), 52.

Ekundayoi, J. A. (2014). Occupational Stress and. International Journal of Scientific Research in Education, 157.

Fals, B. (2009), “Action and Knowledge: Breaking the monopoly with Participatory actionresearch”, intermediate Technology Publication.pp.121-125

Flick, U. (2002) “An Introduction to Qualitative Research”, Sage Publication.pp.12-15

Fraenkel, J. R., Wallen, N. E., \& Hyun, H. H. (1993). How to design and evaluate research in education (Vol. 7): McGraw-Hill New York.

George, D., \& Mallery, M. (2003). Using SPSS for Windows step by step: a simple guide and reference. Boston, MA: Allyn y Bacon.

Guthrie, R (2006), Teachers and Stress. Australia \& New Zealand Journal of Law \& Education, 
Review of Economics and Development Studies, Vol. 6 (4) 2020, 759 - 772

11(1), 5-18.

Han, Y., Kim, Y., \& Hur, W.-M. (2019). The effects of perceived supervisor incivility on child-care workers' job performance: The mediating role of emotional exhaustion and intrinsic motivation. Current Psychology, 1-16.

Hassan, M., Azmat, U., Sarwar, S., Adil, I. H., \& Gillani, S. H. M. (2020). Impact of Job Satisfaction, Job Stress and Motivation on Job Performance: A Case from Private Universities of Karachi. Kuwait Chapter of the Arabian Journal of Business and Management Review, 9(2), 31-41.

Henry, O., \& Evans, A. J. (2008). Occupational stress in organizations. Journal of Management Research, 8(3), 123-135.

Higgins, J.M. (1994), The management Challenge (2nd ed.), New York: Macmillan.

Kahn, R.L., \& Byosiere, (1992). Stress in Organization. In M.D. Dunnette, \& L.M. Hough, (Eds.), Handbook of Industrial and Origination Psychology (Vol.3) (pp.571-650). Palo Alto: Consulting Psychologists press.

Kokoroko, E., \& Sanda, M. A. (2019). Effect of workload on job stress of Ghanaian OPD nurses: The role of coworker support. Safety and health at work, 10(3), 341-346.

Kovach, K. A. (1987). What motivates employees? Workers and supervisors give different answers. Business Horizons, 30(5), 58-65.

Kreitner, R. (1995), Management (6t ed.), Boston: Houghton Mifflin Company.

Kyriacou, C., \& Sutcliffe, J. (1977). Teacher stress: A review. Educational Review, 29(4), 299-306.

Lazarus, R (2003), "From psychological stress to the emotions: A history of changing outlook", Annual Review of psychology.PP.1-21

Lazarus, R. (2006), "From psychological stress to the emotions: A history of changing outlook", Annual Review of Psychology.pp.1-21

Masi, D. A. (1986). Stress and Productivity. The Journal of Nervous and Mental Disease, 174(4), 254 .

Mearns, J., \& Cain, J. E. (2003). Relationship between teacher's occupational stress and their burnout and distress: Roles of coping and negative mood regulation expectancies. Anxiety, Stress, and Coping, 16, 71-82.

Monique, H., Inge, h., and Ajay, B. (2010), “Qualitative Research Methods”, SAGE.pp.91

Moorhead, H. \& Griffin, F. (1998).Organizational Behavior. Boston: Houghton Mifflin Company.

Mughal, S., Walsh, J., \& Wilding, J. (1996). Stress and work performance: The role of trait anxiety. Personality and Individual differences, 20(6), 685-691.

Myer, D. G. (1996). Social psychology (4th ed.). New York: McGraw-Hill.

Naylor, J. (1999), Management, pearson Education, Financial Times/ Prentice Hall, Harlow, United Kingdom, UK.

O’Reilly III, C.A (1991), “Organizational behavior: where we've been, where we're going”, Annual Review of psychology, Vol. 42 pp.427-458.

Omolara, B. E. (2008). Influence of work related stress on organizational commitment at olabisionabanjo university ago iwoyeogun state nigeria. In EABR \& TLC Conference, Rothenburg, Germany, March (pp. 17-20).

Pearson,K. (2007), “On Further Methods of determining Correlation”, Dulau and Company.pp.19

Preacher, K.J., \& Hayes, A.F. (2004). SPSS and SAS Procedures for estimating indirect effects in simple median modls. Behavior Research Methods, Instruments, \& Computers, 36(4), 717731.

Pulak, M. (2012), "Beat that Stress", Express Hospitality. Pp. A-1. Retrieved from:http://hospitality.financialexpress.com/20120615/lifeo1.shtml

Ress,W. D. (1997). Managerial stress - dealing with the causes, not the symptoms, Industrial and Commercial training, 29(2), 35-40. 
Review of Economics and Development Studies, Vol. 6 (4) 2020, 759 - 772

Ricardo, B.,Amy, K., and Rohit, L,. (2007),”Stress at Work”, The Work Foundation.pp.4-7 Robbins, S.P. (2004). Organization Behavior.11th Ed. New Jersey: Pearson Prentice Hall.

Rytkonen, M. H., \& Strandvik, T. (2005). Stress in business relationship. The Journal of Business\& Industrial Marketing, 20(1), 12-22.

Sekaran, U. (2006). Research methods for business: a skill building approach. John Viley \& Sons.

Smith, G.P. (1994), Motivation, In W. Tracey (ed.), Human resources management and development handbook (2nd ed.), New York: Free Press.

Spector, P (2007). E., Allen, T. D., Poelmans, S. A., Lapierre, L. M., Cooper, C. L., Michael, O. D., ... \& Brough, P.. Cross-national differences in relationship of work demand, job satisfaction, and turnover intentions with work family conflict. Personnel Psychology, 6o(4), 805-835.

St-Onge, S., Morin, D., Bellehumeur, M., \& Dupuis, F. (2009). Managers' motivation to evaluate subordinate performance. Qualitative Research in Organizations and Management: An International Journal, 4(3), 273-293.

Swanepoel, B et al (1998). South African Human Resource Management: Theory and Practice. South Africa: Juta \& Co. Ltd.

Swanson, V. (1998) Power, K. G., \& Simpson, R. J. Occupational stress and family life: A comparison of male and female doctors. Journal of Occupational and Organizational Psychology, 71(3), 237-26o.

Taylor, S. (1995). Managing People at Work. London: Reed Educational and Professional

Turbabian, K. (2006), “A manual for Writers of Term Paper, Theses, and Dissertation”, The University of Chicago Press .pp. 67-69

Villanueva, D., \& Djurkovic, N. (2009). Occupational stress and intention to leave among employees in small and medium enterprises. International Journal of Stress Management, 16(2), 124. 